\title{
Synthesis of Functionalized Isoindoles by the Rhodium-Catalyzed Reaction of Cyanoformates with ortho-Borylbenzalacetone Derivatives ${ }^{\dagger}$
}

\author{
Hiroshi Shimizu, Tomohiro Igarashi, and Masahiro Murakami* \\ Department of Synthetic Chemistry and Biological Chemistry, Kyoto University, Katsura, Kyoto 615-8510, Japan \\ *E-mail: murakami@sbchem.kyoto-u.ac.jp \\ Received March 20, 2010, Accepted April 5, 2010
}

Key Words: Isoindoles, Rhodium, Cyanoformates, ortho-Borylbenzalacetone, Azaheterocycles

In the past decade, rhodium-catalyzed addition reactions of organoboron compounds to unsaturated organic functionalities have been intensively investigated. ${ }^{1}$ Organorhodium species generated by transmetallation between boron and rhodium exhibit unique reactivities which are unavailable with other main group organometallics and organotransition metal complexes. We recently reported the synthesis of $\alpha$-keto esters by the rhodium-catalyzed reaction of cyanoformates with arylboronic acids. $^{2}$ An intermediary organorhodium species undergoes 1,2addition regioselectively onto the cyano group of cyanoformate and a resultant iminorhodium species is hydrolyzed to a carbonyl group with loss of the nitrogen atom. This unique reactivity of organorhodium species towards the activated cyano group stands in contrast to the reactivities of arylmagnesium bromide and aryllithium species that attack the ester group of cyanoformates in preference to the cyano group. We next envisaged that it would increase the synthetic utility of the unique reactivity of organorhodium species toward cyano groups if the nitrogen atom of the cyano group could be retained in a reaction product. Thus, the application to the synthesis of aza heterocyclic compounds was next attempted. In this communication, we describe the synthesis of isoindoles by the rhodium-catalyzed reaction of cyanoformate with ortho-borylbenzalacetone derivatives. ${ }^{3}$ The nitrogen atom of the cyano group is incorporated in the produced isoindole skeleton.

Initially, ethyl cyanoformate (2a) was reacted with benzalacetone having a boronic ester group at the ortho position 1a under the reaction conditions we previously reported for the reaction of $\mathbf{2 a}$ with phenylboronic acid (Equation 1$){ }^{2}$ Thus, a mixture of $1 \mathbf{a}$ and ethyl cyanoformate (2a, 1.5 equiv.) in dioxane was heated in the presence of $\mathrm{B}(\mathrm{OH})_{3}(1.0$ equiv.) and $[\mathrm{Rh}(\mathrm{OH})$ (cod) $]_{2}(2.5 \mathrm{~mol} \%, 5 \%$ of $\mathrm{Rh})$ at $80^{\circ} \mathrm{C}$ for $15 \mathrm{~h}$. After aqueous workup, the reaction mixture was analyzed by ${ }^{1} \mathrm{H}$ NMR, which disclosed that the mixture consisted of isoindole $\mathbf{3} \mathbf{a}$, benzal-
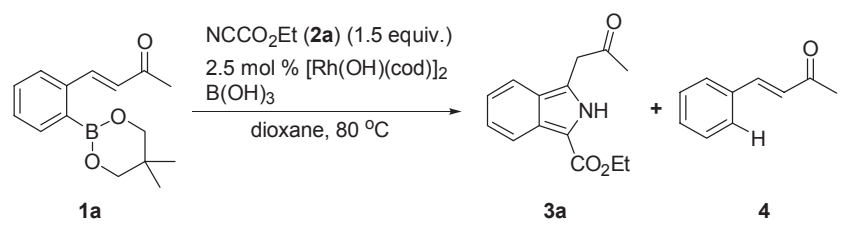

Equation 1. Rhodium catalyzed reaction of 1a with 2a

${ }^{\dagger}$ This paper is dedicated to Professor Sunggak Kim on the occasion of his honorable retirement. acetone (4) and 1a (1a: $\mathbf{3 a}: \mathbf{4}=13: 33: 54)$.

A plausible mechanism for the formation of isoindole $\mathbf{3 a}$ is shown in Figure 1. An arylrhodium species is initialy generated from 1a by transmetallation between boron and rhodium. It undergoes intermolecular 1,2-addition chemoselectively onto the cyano group of $\mathbf{2 a}$. A resultant iminorhodium species undergoes intramolecular conjugate addition onto the electron-deficient alkene at the ortho position in a 5-exo mode to construct a five-membered ring heterocycle, which then undergoes a prototropic shift to establish a pyrrole system with extended conjugation. Finally, a rhodium enolate is protonated to give 3a and the rhodium(I) catalyst. Benzalacetone was formed by direct hydrolysis of the C-B bond of $\mathbf{1 a}$.

The optimization of the reaction conditions revealed that the use of $\mathrm{N}$-methylpyrrolidone (NMP) as the solvent and increasing the amounts of cyanoformate and $\mathrm{B}(\mathrm{OH})_{3}$ to 3.0 equivalents significantly improved the yield of the isoindole $3 \mathrm{a}(75 \%$ isolated yield, Table 1, entry 1). ${ }^{4}$ Thus, the optimal conditions were obtained, and the reaction was examined with a variety of combinations of substrates. Whereas only a moderate yield (57\%) was obtained with methyl cyanoformate (entry 2), isopropyl and isobutyl cyanoformates gave results similar to that of ethyl cyanoformate (entries 3 and 4). The isoindole-forming reaction worked well with substrates having an electron-donating methoxy substituent on the aromatic ring of $\mathbf{1}$ (entries 5 and 6). On the other hand, lower yields were observed when the aromatic ring possessed an electron-withdrawing chloro substituent (entries 7 and 8), probably because protonolysis of the C-B linkage

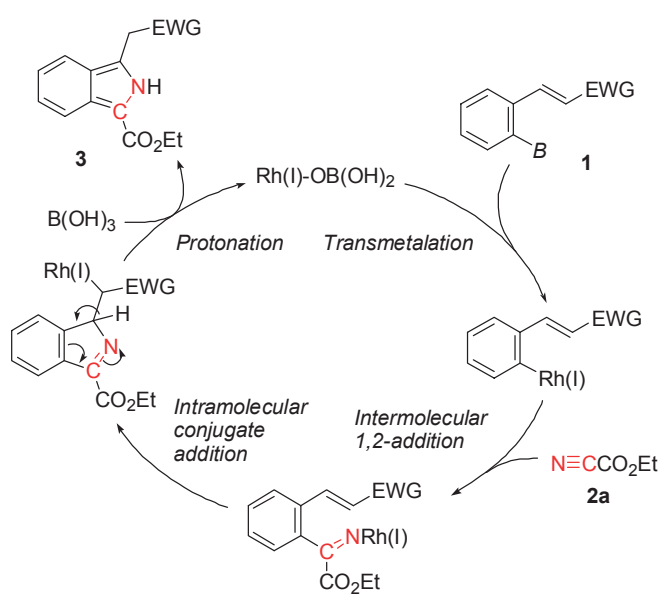

Figure 1. A plausible mechanism for formation of isoindole. 
Table 1. Synthesis of various 3-acylmethyl-2H-isoindoles (3)
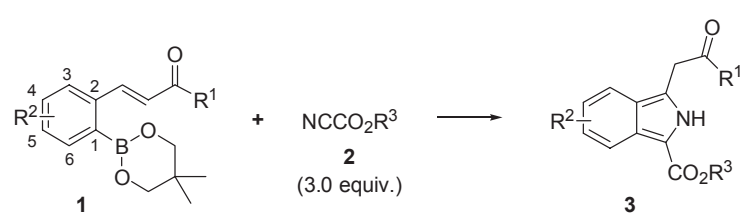

$2.5 \mathrm{~mol} \%[\mathrm{Rh}(\mathrm{OH})(\mathrm{Cod})]_{2}, \mathrm{~B}(\mathrm{OH})_{3} 3.0$ equiv., NMP, $80^{\circ} \mathrm{C}, 3 \mathrm{~h}$

\begin{tabular}{cccccccc}
\hline entry & $\mathbf{1}$ & $\mathrm{R}^{1}$ & $\mathrm{R}^{2}$ & $\mathbf{2}$ & $\mathrm{R}^{3}$ & $\mathbf{3}$ & yield (\%) \\
\hline 1 & $\mathbf{1 a}$ & $\mathrm{Me}$ & $\mathrm{H}$ & $\mathbf{2 a}$ & $\mathrm{Et}$ & $\mathbf{3 a}$ & 75 \\
2 & $\mathbf{1 a}$ & $\mathrm{Me}$ & $\mathrm{H}$ & $\mathbf{2 b}$ & $\mathrm{Me}$ & $\mathbf{3 b}$ & 57 \\
3 & $\mathbf{1 a}$ & $\mathrm{Me}$ & $\mathrm{H}$ & $\mathbf{2 c}$ & ${ }^{i} \mathrm{Pr}$ & $\mathbf{3 c}$ & 72 \\
4 & $\mathbf{1 a}$ & $\mathrm{Me}$ & $\mathrm{H}$ & $\mathbf{2 d}$ & ${ }^{i} \mathrm{Bu}$ & $\mathbf{3 d}$ & 76 \\
5 & $\mathbf{1 b}$ & $\mathrm{Me}$ & $4-\mathrm{MeO}$ & $\mathbf{2 b}$ & $\mathrm{Et}$ & $\mathbf{3 e}$ & 72 \\
6 & $\mathbf{1 c}$ & $\mathrm{Me}$ & $5-\mathrm{MeO}$ & $\mathbf{2 b}$ & $\mathrm{Et}$ & $\mathbf{3 f}$ & 69 \\
7 & $\mathbf{1 d}$ & $\mathrm{Me}$ & $4-\mathrm{Cl}$ & $\mathbf{2 b}$ & $\mathrm{Et}$ & $\mathbf{3 g}$ & 26 \\
8 & $\mathbf{1 e}$ & $\mathrm{Me}$ & $5-\mathrm{Cl}$ & $\mathbf{2 b}$ & $\mathrm{Et}$ & $\mathbf{3 h}$ & 46 \\
9 & $\mathbf{1 f}$ & $\mathrm{Ph}$ & $\mathrm{H}$ & $\mathbf{2 b}$ & $\mathrm{Et}$ & $\mathbf{3 i}$ & 59
\end{tabular}

Table 2. Optimization for the formation of $\mathbf{6} \mathbf{a}$ from $\mathbf{5 a}$ and $\mathbf{2 a}$

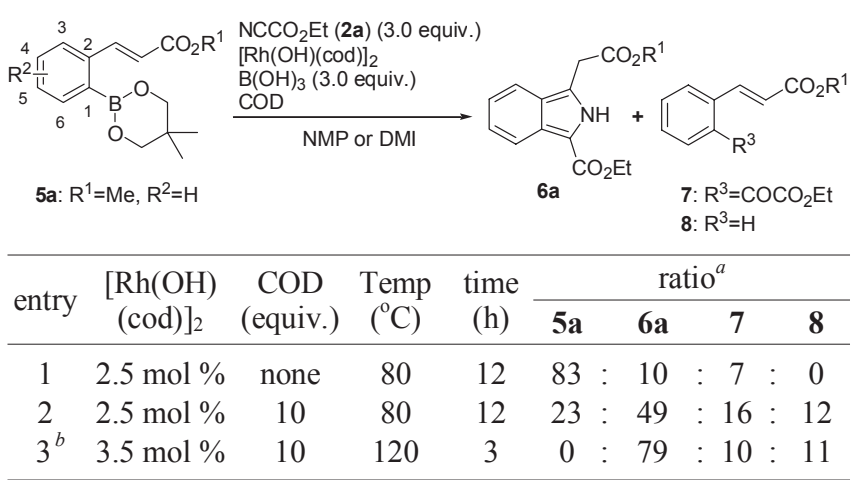

${ }^{a}$ Determined by ${ }^{1} \mathrm{H}$ NMR integral value of crude reaction mixture. ${ }^{b} \mathrm{DMI}$ was employed as solvent.

Table 3. Synthesis of various 3-alkoxycarbonylmethyl-2H-isoindoles $(6)^{a}$

\begin{tabular}{cccccc}
\hline entry & $\mathbf{5}$ & $\mathrm{R}^{1}$ & $\mathrm{R}^{2}$ & $\mathbf{6}$ & yield (\%) \\
\hline 1 & $\mathbf{5 a}$ & $\mathrm{Me}$ & $\mathrm{H}$ & $\mathbf{6 a}$ & 59 \\
2 & $\mathbf{5 b}$ & $\mathrm{Me}$ & $4-\mathrm{MeO}$ & $\mathbf{6 b}$ & 62 \\
3 & $\mathbf{5 c}$ & $\mathrm{Me}$ & $5-\mathrm{MeO}$ & $\mathbf{6 c}$ & 56 \\
4 & $\mathbf{5 d}$ & ${ }^{t} \mathrm{Bu}$ & $\mathrm{H}$ & $\mathbf{6 d}$ & 50
\end{tabular}

${ }^{a}$ The reaction was performed by the condition of entry 3 in Table 2 .

occurred more facilely with these substrates. Not only benzalacetone derivatives but also an analogous chalcone derivative gave the corresponding isoindole (entry 9).

Next, methyl cinnamate having a boronic ester group at the ortho position 5a was used in place of $1 \mathbf{a}$ (Table 2). The $\alpha, \beta-$ unsaturated ester moiety was less reactive as the conjugate acceptor than $\alpha, \beta$-unsaturated ketones, and thus, hydrolysis of the $\mathrm{N}-\mathrm{Rh}$ linkage of the iminorhodium intermediate occurred in competition with intramolecular conjugate addition to the $\alpha, \beta$-unsaturated ester moiety. Hydrolysis of the iminorhodium intermediate gave an iminoester, which was further hydrolyzed to afford the keto ester 7. Formation of the keto ester 7 was suppressed by addition of an excessive amount of cycloocta- diene (COD). The isoindole 6 a was formed in 79\% NMR yield and was isolated in 59\% yield when the reaction was carried out at $120^{\circ} \mathrm{C}$ for $3 \mathrm{~h}$ in 1,3-dimethyl-2-imidazolidinone (DMI) in the presence of 10 equiv of COD and $3.5 \mathrm{~mol} \%$ of $[\mathrm{Rh}(\mathrm{OH})$ $(\mathrm{COD})]_{2}$ (entry 3$)^{5}$ It seems that the rhodium catalyst was deteriorated under the reaction conditions and that the presence of the excessive amount of COD caused its persistent coordination to rhodium, thereby retarding the deterioration of the catalyst.

Other cinnamic ester derivatives were examined and moderate isolated yields ranging from $50 \%$ to $62 \%$ were observed (Table 3).

Recently, isoindoles ${ }^{6}$ have attracted attention in materials science due to their interesting photophysical properties in fluorescence and electroluminescence. ${ }^{7}$ In addition, isoindoles act as the highly reactive diene substrate in [4+2]-cycloaddition reactions employed for preparation of origoacenes. ${ }^{8}$ We have developed a new method to synthesize functionalized isoindole derivatives by the rhodium-catalyzed reaction of cyanoformates with ortho-borylbenzalacetone derivatives. The nitrogen atom of the cyanoformates is incorporated in the isoindole skeleton produced in this reaction.

\section{References and Notes}

1. Reviews: (a) Fagnou, K.; Lautens, M. Chem. Rev. 2003, 103, 169. (b) Hayashi, T.; Yamasaki, K. Chem. Rev. 2003, 103, 2829.

2. Shimizu, H.; Murakami, M. Chem. Commun. 2007, 2855.

3. For the synthetic utilization of ortho-borylbenzalacetone, see: (a) Lautens, M.; Mancuso, J. J. Org. Chem. 2004, 69, 3478. (b) Lautens, M.; Marquardt, T. J. Org. Chem. 2004, 69, 4607. (c) Zhou, F.; Yang, M.; Lu, X. Org. Lett. 2009, 11, 1405.

4. A representative procedure for the synthesis of 3-acylmethyl$2 \mathrm{H}$-isoindole derivatives 3 : To a mixture of $\mathbf{1 a}(78.3 \mathrm{mg}, 0.30$ $\mathrm{mmol}), \mathrm{B}(\mathrm{OH})_{3}(55.6 \mathrm{mg}, 0.90 \mathrm{mmol})$, and $[\mathrm{Rh}(\mathrm{OH})(\mathrm{cod})]_{2}(3.5$ $\mathrm{mg}, 7.7 \mu \mathrm{mol})$ under an argon atmosphere was added a solution of $2 \mathbf{a}(90.1 \mathrm{mg}, 0.90 \mathrm{mmol})$ in NMP $(0.3 \mathrm{~mL})$. After the reaction mixture was stirred at room temperature for $30 \mathrm{~min}$ and then at $80{ }^{\circ} \mathrm{C}$ for $3 \mathrm{~h}$, it was cooled and diluted with a mixed solvent of AcOEt and toluene $(2: 1,5 \mathrm{~mL})$ and $\mathrm{H}_{2} \mathrm{O}(2 \mathrm{~mL})$. The organic layer was separated and the aqueous layer was extracted with the mixed organic solvent $(5 \mathrm{~mL} \times 4)$. The combined extracts were more diluted with the mixed solvent $(25 \mathrm{~mL})$, washed with water $(10$ $\mathrm{mL} \times 3$ ) and with brine, and dried over $\mathrm{Na}_{2} \mathrm{SO}_{4}$. The solvent was evaporated in vacuo. The residue was purified by preparative thin-layer chromatography $\left(\mathrm{CHCl}_{3} / \mathrm{AcOEt}=5 / 1\right)$ to afford 3a (56.1 mg, 75\%).

5. The other boronic esters (esters with ethylene glychol, pinachol, catechol) or boronic acid itself failed to give satisfactory results.

6. (a) Jones, G, B.; Chapman, B, J. In Comprehensive Heterocyclic Chemistry II; Katrizky, A. R., Rees, C. W., Scriven, E. F. V., Eds.; Pergamon: Oxford, U. K., 1996; Vol. 2, pp 1-38. (b) Donohoe, T. J.; Tomas, E. J. In Fused Five-Membered Heteroarenes with One Heteroatom; Georg Thieme Verlag: Vol. 10, Stuttgart, Germany, 2000; pp 653-692.

7. (a) Mi, B.-X.; Wang, P.-F.; Liu, M.-W.; Kwong, H.-L.; Wong, N.-B.; Lee, C.-S.; Lee, S.-T. Chem. Mater. 2003, 15, 3148. (b) Ding, Y.; Hay, A. S. J. Polym. Sci. Part A: Polym. Chem. 1999, 37, 3293. (c) Gauvin, S.; Santerre, F.; Dodelet, J. P.; Ding, Y.; Hlil, A. R.; Hay, A. S.; Anderson, J.; Armstrong, N. R.; Gorjac, T. C.; D’Iorio, M. Thin Sold Films 1999, 353, 218. (d) Matuszewski, B. K.; Givens, R. S.; Srinivasachar, K.; Carlson, R. G.; Higuchi, T. Anal. Chem. 1987, 59, 1102. (e) Zweig, A.; Metzler, G.; Maurer, A.; Roberts, B. G. J. Am. Chem. Soc. 1967, 89, 4091.

8. (a) Duan, S.; Sinha-Mahapatra, D. K.; Herndon, J. W. Org. Lett. 2008, 10, 1541. (b) Chen, Y.-L.; Lee, M.-H.; Wong, W.-Y.; Lee, A. W. M. Synlett 2006, 2510. (c) Chen, Z.; Muller, P.; Swager, T. M. Org. Lett. 2006, 8, 273. (d) LeHoullier, C. S.; Gribble, G. W. J. Org. Chem. 1983, 48, 2364. 